\title{
SALVANDO LAS ÁNIMAS. DISCURSOS DE GÉNERO Y RELIGIÓN EN LAS REVISTAS DE LA ACCIÓN CATÓLICA ESPAÑOLA ${ }^{1}$
}

\section{Resumen}

En este artículo se presenta, a través del binomio categórico género y religión, un análisis de tres revistas femeninas editadas por la Acción Católica Española (ACE) en las décadas de 1940 y 1950: Volad. Revista de las Muchachas Inteligentes, dirigida a las jóvenes católicas; Para Nosotras. Revista para Obreras, destinada a las trabajadoras; y Ecclesia, orientada a un público más amplio, a mujeres y hombres católicos. El propósito de este trabajo es establecer una conexión entre los discursos difundidos desde el catolicismo, en especial, desde su organización más destacada, la ACE, y la consolidación de un modelo de género que asumió el franquismo como propio. Pero, por otra parte, se pretende señalar el rol de las católicas en la difusión de esos discursos de género y en el cuestionamiento de la supuesta separación establecida históricamente entre lo público y lo privado. Esta investigación se llevó a cabo por medio del análisis de documentos procedentes del Archivo de la Acción Católica Española y de la Biblioteca Nacional de España.

Palabras clave: Acción Católica española, revistas femeninas, género, religión, franquismo.

\section{Resumo}

Salvando as almas. Discursos de género e religião nas revistas de Ação Católica Espanhola

Neste artigo apresentamos, através do binômio categórico género e religião, uma análise de três revistas femininas publicadas pela Ação Católica Espanhola (ACE) durante as décadas de 1940 e 1950: Volad. Revista de las Muchachas Inteligentes, dirigida às jovens católicas; Para Nosotras. Revista para Obreras, destinada às trabalhadoras; e Ecclesia, orientada para um público mais amplo, a mulheres e homens católicos. O objetivo deste artigo é estabelecer uma conexão entre os discursos difundidos do catolicismo, especialmente de sua organização mais proeminente, a ACE, e a

1 Este texto forma parte de una investigación financiada por la Comunidad de Madrid, en el marco de las Ayudas destinadas a la Atracción de Talento Investigador y del apoyo del Grupo de Investigación de Historia Social y Cultural Contemporánea (Universidad Autónoma de Madrid) y del Proyecto Intercambios culturales y creación de identidades a través de fuentes literarias, siglos XIX y XX (MINECO HAR2016-76398-P), coordinado por las profesoras Pilar Toboso y Carmen de la Guardia (UAM). Universidad Complutense de Madrid, 28040 Madrid, España.

Dirección postal: Av. Séneca, 2, 28040 Madrid, España.

Correo electrónico: sarmar02@ucm.es

** Departamento de Historia Contemporánea, Facultad de Filosofía y Letras, Universidad Autónoma de Madrid, 28049 Madrid, España.

Dirección postal: Campus de Cantoblanco, Calle Francisco Tomás y Valiente, 1, 28049 Madrid, España.

Correo electrónico: gabriela.lima@uam.es 
consolidação de um modelo de género que assumiu o regime de Francisco Franco como seu. Porém, por outro lado, pretendemos destacar o papel dos católicos na disseminação desses discursos de género e, também, no questionamento da suposta separação estabelecida historicamente entre o público e o privado. Esta investigação foi realizada através da análise de documentos do Arquivo da Ação Católica Espanhola e da Biblioteca Nacional da Espanha.

Palavras-chave: Ação Católica Espanhola, revistas femininas, género, religião, Franquismo.

\section{Abstract \\ Saving the souls. Gender discourses and religion in the Spanish Catholic Action's magazines}

This article presents, through the categorical binomial gender and religion, an analysis of three women's magazines published by the Spanish Catholic Action (ACE) in the 1940s and 1950s: Volad. Revista de las Muchachas Inteligentes, for young women; Para Nosotras. Revista para Obreras, for women workers; and Ecclesia, oriented to a wider audience, to Catholic women and men. The purpose of this paper is to establish a connection between the discourses spread from Catholicism, especially from its most prominent organization, the ACE, and the consolidation of a gender model that assumed the Franco regime as its own. On the other hand, we intend to point out the role of Catholics in the dissemination of these gender discourses, and in questioning of the alleged separation between the public and the private sphere. This investigation was carried out through the analysis of documents from the Spanish Catholic Action and the Spanish National Library.

Keywords: Spanish Catholic Action, women magazines, gender, religion, Francoism.

\section{Introducción}

El presente artículo es resultado del estudio de algunas de las revistas publicadas por la Acción Católica Española (ACE) y de la reflexión en torno a los significados históricos de los discursos sobre género durante el franquismo, especialmente aquellos construidos por una de las «familias» del régimen: la católica. María Pilar Salomón (2000) y Mónica Moreno (2005) apuntan que la historiografía ha dejado en un segundo plano las manifestaciones del catolicismo femenino e invitan a la incorporación de la categoría de género en los estudios que conciernen al ámbito religioso. En este sentido, la teoría feminista ha pasado a formar parte de un desafío epistemológico central para los historiadores y las historiadoras que buscan reconstruir las trayectorias, los discursos y representaciones de las mujeres. Comprendemos, como ha señalado Carmen Silva (2013), la importancia de la teoría feminista para cuestionar la normalización patriarcal, comprender y explicar los mecanismos utilizados para silenciar a las mujeres e identificar las estructuras sociales y los procesos de interacción que sostienen discursos, pensamientos y símbolos masculinos de una forma hegemónica. Según Ortega (1988, 41-48) y Salomón (2000, 237), el análisis de género permite detectar la especificidad de las experiencias de las mujeres y, al mismo tiempo, establece una profundización de 
las atribuciones y cualidades que cada sociedad asigna a lo masculino y femenino, y las relaciones de poder derivadas entre los sexos y en la sociedad.

Además del enfoque género para el análisis planteado en este artículo, el concepto de religión resulta de similar trascendencia. Ambos han sido definidos y redefinidos en diferentes contextos y, a la vez, han incorporado diferentes significados históricos, político-culturales y sociales a lo largo de la historia. Partiendo de las interpretaciones de Inmaculada Blasco Herranz (2003 y 2005a) y Raúl Mínguez (2014) sobre el binomio género-religión, tenemos la pretensión de incorporar desde las revistas católicas un análisis sobre los discursos y las prácticas en relación con las mujeres bajo el Estado franquista. Como señala Raúl Mínguez, siguiendo a Birgit Heller, «el análisis de los modelos de género vigentes en cada época histórica no debe olvidar la importancia que juega la religión en la conformación de una sociedad o una cultura determinada» (Mínguez 2014, 45), razón por la cual resulta imprescindible tejer un hilo entre las investigaciones sobre las mujeres, los estudios de las religiones y la perspectiva de género.

Raúl Mínguez $(2014,29)$, por otra parte, señaló que el catolicismo español no construyó el arquetipo de feminidad «católico», sino que bautizó al modelo liberal previo con una ideología y valores católicos a partir del Concordato de 1851. La Iglesia, en su intento por aunar rupturas y continuidades, permutas y persistencias en la modernidad, decidió asumir estratégicamente a través de sus discursos el modelo femenino asociado al matrimonio y a la maternidad, convirtiendo así a las mujeres en madres de la sociedad católica del futuro. Posteriormente, el franquismo confluiría ideológicamente con estas atribuciones asignadas a las mujeres desde la religión, específicamente, desde el catolicismo, en su rol social como amas de casa, cuidadoras y esposas. De hecho, la perspectiva antifeminista fue una parte esencial de las creencias franquistas y, por supuesto, de la religión católica, su aliada. La religión católica llevó a cabo una forma de sacralización de la política, en que el Estado franquista se convirtió en una entidad sagrada, en cuanto a su misión de reconquista del espíritu y del intento de reinstaurar, según Ismael Saz (2013), un nuevo orden a través de la doctrina católica. Al considerar el catolicismo un rasgo intrínseco del ser español, se equiparó la religión católica con la identidad nacional. Esta fusión teórica de nación y fe se convirtió en seña de identidad de la dictadura (Maza Zorilla 2014, 170).

La religión católica permitió así una socialización eficaz del discurso y de la ideología del nuevo régimen, sobre todo a partir del discurso católico formulado por los integrantes de la ACE. Durante la década de 1940, con la adaptación del régimen a un contexto de patente declive del fascismo, se dio paso a un proyecto reaccionario de influencia católica con el cual el franquismo pasó a identificarse plenamente (Saz 2003, 266). ${ }^{1}$ De esta forma, nuestro análisis se centrará en el Pri-

La influencia política-social que el catolicismo adquirió vino a sustituir la influencia política que, hasta entonces, ejercía el sector falangista. La pérdida de influencia pública de los falangistas radicales reveló el inicio del declive del proyecto falangista (Botti 1992, 118). 
mer Franquismo; es decir, durante la década de la década de 1940 y hasta finales de la de 1950, cuando el nacionalcatolicismo entró en declive y cedió paso al período de la tecnocracia (1957-1969). Dentro de esa dinámica de las décadas estudiadas, la ACE apostó por una mayor difusión de sus dogmas a través de la prensa. En la década de 1950, de las 847 revistas católicas que se editaron en España, cien pertenecían a la Acción Católica (Orbegozo Urruella 1957). Todas las publicaciones siguieron la línea pastoral diseñada por la jerarquía eclesiástica y, además, muchas de ellas orientaron sus discursos hacia las mujeres y las jóvenes, ya fueran obreras o de clase media y alta. En este trabajo, analizaremos tres revistas editadas por la ACE: la revista Ecclesia, creada en 1941; Para Nosotras, en 1944; y la revista Volad, editada desde 1946.

En este artículo, pues, nos apoyaremos en los discursos construidos sobre el género a través de las tres revistas mencionadas, aunque haremos referencia a otras como Senda, órgano nacional de la rama de Mujeres de Acción Católica, que fue editada a partir de 1941. Algunos investigadores han abordado ya en profundidad los discursos y agencia de la rama de Mujeres de la ACE durante el Primer Franquismo (Álvarez Rodrigo 1999; Blasco Herranz 2003, 2005b, 2005c; Moreno Seco 2003; Pérez del Puerto 2015), señalando las contradicciones existentes entre los discursos de la domesticidad y el papel activo desempeñado por muchas de las dirigentes, algunas de las cuales no contrajeron matrimonio y dedicaron toda su vida a la labor en la ACE (Salas 1959). Según Moreno Seco, «los discursos y prácticas de las mujeres de Acción Católica [...] contribuyeron a reformular o a reafirmar, según el caso, las identidades de género de la cultura política nacional católica» $(2012,169)$, de manera especial durante los tempranos años de la dictadura y hasta el despegue que protagonizaron las bases militantes y las dirigentes de la ACE tras la Semana Impacto de 1959 (Martín Gutiérrez 2017a, 217). Por esta razón, en este artículo pretende analizarse si estas conclusiones contempladas para las mujeres adultas pudieran extrapolarse o encontrar similitudes en otros sectores femeninos de la población española para la misma época histórica.

Las publicaciones femeninas fueron importantes instrumentos de transmisión del modelo de mujer que difundía el régimen franquista. Estas revistas son una herramienta clave para entender los discursos de género orquestados desde el catolicismo hacia las mujeres españolas, pero, por otra parte, también permiten analizar la agencia de las mismas. En las revistas Para Nosotras, Volad y Ecclesia se encuentra, por lo tanto, importante información sobre los discursos que delimitaron los modelos de comportamiento que el franquismo consideraba adecuados para las españolas. Los criterios clave a la hora de escoger qué revistas se incluirían en nuestro análisis fueron, en primer lugar, que fueran editadas dentro del marco cronológico de ascenso y declive del nacionalcatolicismo; en segundo lugar, que las publicaciones fueran revistas o boletines internos de diferentes ramas de la ACE y estuvieran dirigidas a distintos públicos, para valorar si cuestiones como el origen de clase modificaban notablemente la orientación de los discursos. Por último, se estimó que todas tuvieran periodicidad mensual y una difusión amplia: 
Para Nosotras, la única revista católica dirigida a las mujeres de clase trabajadora; Volad, orientada a un público joven pero que mantenía una estética, contenido y propósitos semejantes a la revista Senda dirigida a las mujeres adultas, ${ }^{2}$ y, por último, Ecclesia, que, al ser la revista más difundida de la ACE, estuvo dirigida tanto a mujeres como a hombres adultos.

\section{Acción Católica Española: los discursos de género en las páginas de sus revistas}

La llegada del general Francisco Franco al poder implicó la restauración social católica. En un régimen fascistizado y confesional claramente vinculado al nacionalcatolicismo, ${ }^{4}$ la Iglesia pasó a considerar que el control directo de las lecturas habría de ser exclusivamente suyo. Preocupada por su responsabilidad moral y ansiosa por afianzar el nacionalcatolicismo, la Iglesia buscó ejercer su control por medio de la prensa. A través de sus revistas, intentó orientar las lecturas de los seglares, y éstas tuvieron un papel clave en la defensa de los valores pregonados por la Iglesia respecto a su concepción de género. La Iglesia española actuó en dos frentes: por una parte, combatió la subversión del orden simbólico y, por la otra, colaboró con el Estado mediante el control de la vida de las personas en el ámbito privado. En este marco, las revistas editadas por la Iglesia, como Ecclesia, Volad y Para Nosotras apostaron por convertirse en agentes moralizantes de la sociedad a través de sus páginas, difundiendo un arquetipo de género alineado con los valores católicos, aunque edulcorado con artículos más livianos y de entretenimiento para lograr una mayor distribución incluso entre el público no católico.

La ACE fue una de las fórmulas asociativas católicas más activas en el mundo laico, de carácter apolítico, pero estrechamente vinculada a la jerarquía eclesial local y a los mandatos de Roma (Montero 2009, 160). Había sido concebida para recatolizar y frenar el proceso de secularización de las instituciones y de la cultura que había comenzado a finales del siglo XIX. En el caso de España, la Acción Católica femenina había crecido en la década de 1920 de la mano del cardenal Guisasola. La actividad de las «damas» católicas encontraba claras reminiscencias en el modelo italiano que había impulsado Lucia Spada, la María de Echarri italiana, en la Unione Femminile delle Donne Cattoliche (Preziosi 1996). El objetivo de ambos

2 El Consejo Superior de las Jóvenes de Acción Católica editaría a partir de 1955 una revista femenina de nombre Alba con similares propósitos. No obstante, no se ha estimado su análisis al tener un menor recorrido e influencia que Volad.

3 Entendiendo por tal al que tiene componentes y referentes fascistas no hegemónicos, pero sin los cuales no se puede captar su naturaleza y dinámica (Saz, 2013).

$4 \quad$ El nacionalcatolicismo caracterizaría al Nuevo Estado en el que la religión representaba el «cimiento de la unidad y la identidad nacional, la identificación con la España ortodoxa [...], la exaltación de un pasado imperial mítico vinculado a una concepción de la historia como resultado del designio de la providencia» (Di Febo 2004, 84). 
movimientos de mujeres era la defensa de los valores tradicionales en contraposición a los nuevos postulados enunciados por los movimientos feministas europeos (Blasco Herranz 2005c 117). La protección de la familia frente al divorcio en el caso italiano, la educación religiosa frente al modelo laico, y el amparo del arquetipo de género burgués conocido como «ángel del hogar», en definitiva, el antagonismo entre grises de la modernidad y la tradición.

La rama de Mujeres de la ACE había reducido en los tiempos republicanos la actividad política desarrollada en la década anterior, orientando sus propósitos más hacia actividades apostólicas y evangelizadoras con el objetivo de consolidar la influencia de la organización (Blasco Herranz 2008a, 60-62). En 1941, el proceso de formación de las comisiones diocesanas de las Mujeres de la ACE parecía culminado, y en su estructura comenzaron a funcionar diferentes secretariados orientados a la beneficencia y la moral, entre ellas una dirigida a la captación de las obreras. Estas consignas, en sintonía con los valores católicos, se difundieron a través de la estructura de propaganda y publicaciones de la ACE. Las revistas para mujeres desarrollarían a partir de la década de 1940 la función del control social a través de sus páginas y la difusión de unos discursos de género coincidentes con los del nuevo régimen dictatorial de Francisco Franco (Muñoz Ruiz 2003, 102).

\section{El modelo de madre obrera cristiana y la revista Para Nosotras}

Para cumplir con su cometido doctrinal con las mujeres de clase trabajadora, la ACE editó a partir de 1944 la revista Para Nosotras. ${ }^{5}$ La cotidianeidad de las obreras se reflejaba en la sección Hogar junto con recetas de cocina y consejos para la limpieza. La revista enseñaba catecismo a través de diferentes fragmentos de la encíclica del Papa León XIII, la Rerum Novarum, y otros postulados eclesiales sobre la clase obrera. Para Nosotras solía incluir informaciones sobre los derechos y deberes de los obreros y patronos, así como la normativa legal del nuevo régimen. ${ }^{6}$ Una cuestión que entraba en cierta contradicción con los discursos de la domesticidad, ya que reconocía indirectamente que muchas de las mujeres de clase trabajadora, casadas o solteras, realizaban algún tipo de trabajo asalariado fuera del hogar. Sobre ellas la ACE ejercía el tradicional paternalismo que le caracterizaba, considerando a las obreras especialmente vulnerables, iletradas pero bondadosas por su «falta de conciencia» (Blasco Herranz 2008b, 261).

La revista buscaba la combinación de contenidos recreativos y sencillos para captar lectoras entre las obreras mientras cumplía su función educativa con la

\footnotetext{
5 Se esperaba que las mujeres se mantuvieran fuera de toda actividad susceptible de ser peligrosa e inmoral, por ejemplo, los bailes modernos, las malas compañías o el cine. A ellas se les recordaba qué visionado de películas se encontraba fuera de lo moralmente permitido. Para Nosotras, 27, jul 1946.

6 Para Nosotras, 11, enero 1945.
} 
difusión de secciones relacionadas con el catecismo y la moralidad. La publicación servía de apoyo a la actividad propagandística de los Centros Obreros que había puesto en marcha la ACE a partir de 1941 en algunas diócesis (Moreno Seco 2011) y recogía las inquietudes y el devenir de algunos grupos ya consolidados, detallando las actividades que celebraban y animando a otros centros y parroquias a realizar retiros y ejercicios espirituales, excursiones al campo, convivencias, cursillos o formación profesional, como cursos de corte y confección o cocina en los locales de la ACE. Para Nosotras se transformaba en altavoz de la doctrina católica en el mundo del trabajo. Como recordaba Lucía García -una obrera posteriormente vinculada a la Hermandad Obrera de Acción Católica Femenina (HOACF)-, las «damas» profesaban la tutela de la moralidad y las buenas costumbres: «se acercaban a hablar de moral franquista a las jóvenes obreras». ${ }^{\text {? }}$

La ACE puso especial énfasis en recrear situaciones cotidianas problemáticas de las familias obreras, demostrando a las madres desde el paternalismo y el imaginario - que dudaba de su capacidad autónoma, paradójicamente- cómo proceder en las mismas. Para Nosotras buscaba también acercarse a la obrera más joven, razón por la cual promovió la puesta en marcha de una sección dedicada a las solteras cuya importancia del matrimonio se reflejaba en cada número.

Para Nosotras se proponía acercar a la obrera hacia una religión diferente a la que habían vivido su madre y su abuela, más espiritual y menos ritualista, pero recogiendo las enseñanzas para la madre obrera: «iQué buena madre! No te contentes con eso si, además de madre buena, quieres ser madre cristiana». ${ }^{8}$ El modelo de la Virgen María continuaba siendo el arquetipo más importante para la rama de Mujeres de la ACE, al ser el ejemplo de esposa cristiana por excelencia y encarnar los valores católicos por antonomasia. De ella se destacaba su dedicación al hogar, al cuidado de su esposo y de su hijo, cumpliendo siempre sus tareas con un carácter puro, humilde, sencillo y de entregado servicio a la familia. La actividad de la Virgen María se erigía, así, como prototipo y fiel espejo en el cual las obreras católicas debían reflejarse:

Su trabajo se deslizaba entre la oración y el trabajo, y los días de fiesta su descanso sería acompañar a José. [...] La esposa del obrero había sido elevada a la categoría más alta a que podía llegar una criatura humana: a ser madre de Dios y bendita entre todas las mujeres de la tierra. ${ }^{9}$

Desde la ACE, se enunciaron los dos modelos de mujer opuestos entre sí: María y Eva, y se animó a las mujeres a emular el arquetipo de la Virgen María, cuyas virtudes de servicio, pureza y castidad debían convertirse en estandarte para las nuevas militantes obreras:

\footnotetext{
Entrevista a Lucía García realizada por José Babiano, Madrid, 2007, Archivo Historia del Trabajo, Fundación Primero de Mayo, Serie Biografías Obreras.

Para Nosotras, 2, abr 1944.

Para Nosotras, 3, mayo 1944.
} 
¿Eva o María? Saben ser alegres y graciosas en sus conversaciones sin manchar sus labios con palabras o chistes impuros o ligeros; visten con elegancia y buen gusto sin descender a inmodestias; se divierten sin necesidad de ponerse en peligro de pecar. También la casta de María continúa en esas chicas que pueden llamarse con verdad Hijas de María ¿Tú a qué casta perteneces? ¿A la de Eva? ¿A la de María? ${ }^{10}$

Según defendían los editores de la revista Para Nosotras: «El puesto de honor de las mujeres es el hogar, atendiendo a su marido y ocupándose de sus hijos, y sólo así podrá ser feliz», un modelo que emulaba la figura de la Virgen María. ${ }^{11}$ De esta forma, mientras las damas de la ACE animaban a la participación de las obreras en los espacios de socialización católicos, en los centros obreros y en lo que a partir de 1947 sería la HOACF (Moreno Seco 2011; Martín Gutiérrez 2016 y 2017b) se recordaba también en diferentes secciones de la revista el importante rol de madre y esposa de las trabajadoras asalariadas y de las compañeras de los obreros, pues bajo la identidad obrera se cobijaban todas ellas, aunque no cumplieran con un trabajo extradoméstico (Martín Gutiérrez 2017a, 384). En este aspecto se encontraba otra de las contradicciones, pues desde los discursos católicos emulados desde Roma, el matrimonio se consolidaba ipso facto como la vía más honrosa y apropiada para las mujeres. No obstante, no fueron pocas las ocasiones en las que obreras desarrollaron una actividad asalariada extradoméstica, fundamentalmente cuando la situación familiar era especialmente difícil y se hacía necesaria la entrada de un segundo jornal al hogar, sin olvidar el caso de solteras y viudas, que preferentemente desempeñaron una actividad laboral, ya que tenían menos restricciones legales. En este sentido, en no pocas familias obreras, la miseria y la escasez de alimentos y bienes de primera necesidad condujo a muchas mujeres a aceptar puestos de trabajo en los que su salario era mucho más bajo que el de sus compañeros (Martín Gutiérrez 2017b, 454). Otras desarrollarían una actividad asalariada en distintas actividades de la economía sumergida y en el trabajo a domicilio, principalmente para el sector textil a diferencia de muchas mujeres de clase acomodada que militaban en la ACE.

Si bien la ACE consideraba que su deber hacia la obrera era recordarle su principal misión en el hogar como madre y esposa de la familia católica, lo cierto es que también el apostolado iba a favorecer por otro lado -y de manera inevitable- el inicio de una actividad eclesial que trasladaba a las mujeres a un espacio de socialización alejado de los muros domésticos: la Iglesia, y, posteriormente los barrios, un proceso que también experimentaron las dirigentes y afiliadas a la rama de Mujeres de la ACE (Blasco Herranz, 2003). Esta actividad se constituía entonces como extensión del cuidado de la unidad familiar fuera de la morada, pero, de alguna manera, en estrecha vinculación con la sociedad conservadora. Dicho aspecto ya se encontraba a comienzos del siglo XX en las actividades del catolicismo social. En el caso específico de las mujeres, éste se asociaba directamente con

\footnotetext{
$10 \quad$ Para Nosotras, 32, dic 1946.

11 Para Nosotras, 5-6, jul/ago de 1944.
} 
el paso de la maternidad familiar a la maternidad social que había enunciado Concepción Arenal en el siglo XIX y el primer asistencialismo desarrollado por las damas católicas de la alta burguesía. En este nuevo modelo de madre, las mujeres de la mesocracia y algunas seglares habían realizado todo tipo de actividades «sociales» fuera del hogar, entre ellas, visitas a las prisiones y a los enfermos. También habían impulsado las primeras obras sociales para afiliar a las trabajadoras asalariadas de la mano de María de Echarri. ${ }^{12}$ El perfil de estas mujeres asistencialistas se encontraba ligado a la educación, pues algunas ejercían como maestras, siendo este el perfil mayoritario de muchas Mujeres de la ACE que participaban de la coordinación y formación en distintos centros católicos, mientras que en numerosos casos las obreras habían abandonado sus estudios a una edad temprana para trabajar o eran analfabetas. Las «damas» gestionaron las primeras campañas asistencialistas dirigidas a las capas más desfavorecidas de la sociedad, como señalaban algunas dirigentes de la ACE en la revista Senda:

La mujer obrera creyente está necesitada de un apoyo moral que la ayude a defenderse del ambiente desmoralizador en el que tiene forzosamente que vivir, y este apoyo lo encontrará en la organización [...], la AC les dará la formación necesaria para que conozcan en cada momento lo que deben hacer, y luego la organización les servirá de apoyo, de defensa, de fortaleza en los momentos duros de la lucha contra el mal [...]. Preparar a la mujer para que cumpla bien sus deberes de esposa y madre es el gran campo del apostolado que le ofrece a nuestra vista. ${ }^{13}$

La Acción Católica femenina continuaría con esta estela de manera más intensa en los años previos y venideros a la dictadura franquista y si bien en la década de 1940 se dificulta contemplar una agencia de las mujeres muy diferente a los discursos de género orquestados desde el catolicismo social, bien es cierto que para la década de 1950, con el desarrollo de la HOACF, las obreras irían cobrando un protagonismo importante a nivel social, gracias a los métodos de formación de orientación jocista que se asumieron en la organización, alejados del nacionalcatolicismo (Moreno Seco 2011; Martín Gutiérrez 2016, 76).

\section{La revista Volad y el modelo de joven católica de buena familia}

La ACE contó con el amparo del régimen, evitando la censura oficial de sus publicaciones, un aspecto indispensable para la difusión de sus discursos de

12 María de Echarri había desempeñado un papel clave en el sindicalismo religioso de comienzos del siglo XX, en la dirección de la Confederación Nacional de Sindicatos Obreros Femeninos que fue impulsada en 1924. Luchó activamente por la mejora de las condiciones laborales de las obreras, liderando algunas demandas como la que posteriormente se recogería en el marco legal: «La Ley de la Silla» de 1912 (Morcillo 2012, 58).

13 Senda, n. ${ }^{\circ}$ 35, junio de 1944.

ex æquo, n. ${ }^{\circ}$ 37, 2018, pp. 63-80. DOI: https://doi.org/10.22355/exaequo.2018.37.05 
género a través de sus boletines y folletos. Precisamente otra de las revistas que salieron del servicio de divulgación de la ACE fue la revista Volad. Revista de las muchachas inteligentes, una fórmula con claros tintes moralizantes dirigida a las jóvenes españolas que en el año 1952 costaba 2 pesetas cada número y que estaba editada mensualmente por el Consejo Superior de las Jóvenes de la ACE. Aunque había comenzado su andadura en 1936, no fue hasta el final de la década de 1940, en 1946, cuando volvería a editarse. Revista de periodicidad mensual y de carácter institucional, su tirada para el bienio 1955-1957 había sido de 14000 ejemplares.

La rama de Jóvenes de la ACE destinó sus esfuerzos a apoyar a las pocas estudiantes universitarias españolas con actividades moralistas y patrióticas y sostuvo a la rama de Mujeres de la ACE en su actividad propagandística con las trabajadoras a través de talleres de alfabetización y otros cursillos de formación: «Los objetivos de estos esfuerzos educativos y de ocio eran claros: por un lado formar a sus socias para erigirse como una élite de chicas puras y virtuosas que sirviesen como modelo al resto de jóvenes de la sociedad española de la época, gravemente corrompidas por la «libertad de costumbres» durante la República (Pérez del Puerto 2012, 7). En definitiva, Volad compartía con el resto de publicaciones de la ACE el afán por la moralización de las mujeres y el control sobre su comportamiento.

Al igual que sucedía en la mayoría de volúmenes dirigidos al sexo femenino, Volad ejerció de agente moralizador cuestionando la libertad de las mujeres y manifestando la necesidad de castigo para aquellas adolescentes traviesas que no cumplían con el modelo de abnegación, responsabilidad y buen hacer que enunciaba la revista (Muñoz Ruiz 2002, 79). Enfocada en las palabras en detrimento de las ilustraciones, tan presentes en otras publicaciones, descubría algunas historias amplias en forma de reportajes y pequeñas «novelas» o historias breves donde las jóvenes eran las protagonistas. A través de ellas, la ACE difundía una moraleja orientada al mantenimiento de los valores católicos: disciplina, respeto, amistad femenina, verdad y compañerismo, entre otros, muchas veces sobre el relato de relaciones afectivas e historias familiares (Muñoz Ruiz 2002, 102). La revista presentaba también secciones de actualidad mundial y temas culturales sobre historia, artes, geografía o música, utilizando un lenguaje mucho más extenso y elaborado, adaptado a un público con un nivel educativo superior a la media española (Vilanova y Moreno 1992). ${ }^{14}$ Además, muchos de sus artículos estaban firmados por mujeres, algunas de ellas pertenecientes a los movimientos de la ACE. En cada número divulgaba información de actividades asistencialistas y algunas misiones católicas en países de África o América, una realidad que debían conocer las jóvenes. ${ }^{15}$

A diferencia de la revista dirigida a las obreras, donde aparecía una sección de corte y confección donde podían aprender patrones para coser su propia vestimenta, en Volad ya se encontraban presentes a partir de la década de 1950 diferentes artículos de consumo de moda y belleza que destacan sobre los pocos patrones 
que se hallaban en sus páginas, en un claro elemento diferenciador de clase. Volad también combinaría un contenido destinado en exclusiva a las mujeres: recetas de cocina, canciones, poemas, recomendaciones de lecturas («los libros, al igual que los amigos, hay que saber elegirlos», diría la ACE $)^{16}$ o sugerencias de actividades para la realización personal. Todo ello combinado con notas de contenido religioso que recordaban a las jóvenes las verdaderas virtudes femeninas: la generosidad, el sacrificio o el respeto a la autoridad (Muñoz Ruiz 2002, 103-104). La censura de las lecturas, presente en buena parte de las revistas eclesiales, se reflejaría también en las palabras del sacerdote E. Enciso, quien recomendaba lecturas «selectas» en la revista Volad: «No creo que las novelas sean los mejores libros para formar personas cultas y completas», diría en $1956 .{ }^{17}$

Al igual que sucedía en Para Nosotras, la buena conducta de las jóvenes se encontraba orientada al mantenimiento de la armonía familiar, a la conformación de una identidad adulta y a la búsqueda de un matrimonio apropiado. A ellas se les recordaba que debían escoger un pretendiente con buenos valores católicos, moralista, nada pretencioso o materialista. Para ello, Volad concedía algunos consejos a las adolescentes con la pretensión de consolidar un buen noviazgo: no salir en exceso ni frecuentar lugares como los cines, no hablar mucho o cuidar su imagen física con decoro (Colmenero 2014, 144-145).

A pesar de su contenido, menos formativo, aunque sí moralizador a través de la narración y los contenidos de «ocio», las alusiones a la Virgen María serían recurrentes. Los valores que difundía la revista eran aquellos que coincidían con los encarnados en la figura de María, el referente por antonomasia del mundo católico femenino.

En 1952, la revista se constituía como espacio de socialización con el impulso del Club diezmilistas. Además, a través de su sección Para qué sirves, la ACE presenta diferentes carreras profesionales, algunas relacionadas con el mundo de las artes, otras con el cuidado, como la asistencia social, y otras con el mundo mercantil, otro aspecto que entraba en cierta contradicción con el modelo de maternidad exclusivo, si bien es cierto que estaba dedicado a las más jóvenes y se estimaba que cuando éstas contrajeran matrimonio se dedicarían en exclusiva a sus tareas familiares. Para todas ellas definía una serie de destrezas, cualidades y valores, y su propósito era orientar a las lectoras hacia un desempeño laboral acorde a su carácter y habilidades.

En 1954, la revista alcanzaría una tirada de 10000 ejemplares, iniciando durante estos últimos años un cambio de formato, mucho más moderno y similar a las revistas femeninas generalistas. ${ }^{18}$ La Iglesia una vez más demostraría adaptación a los nuevos tiempos adecuando su contenido a las distintas formas de sociabilidad que se desarrollarían ya a comienzos de la década siguiente.

Volad, 75, sep 1952.

Volad, 116, feb 1956.

Volad, 96, jun. 1954.

ex æquo, n. ${ }^{\circ}$ 37, 2018, pp. 63-80. DOI: https://doi.org/10.22355/exaequo.2018.37.05 


\section{La revista Ecclesia: la portavoz de los valores pregonados por la ACE}

La revista Ecclesia fue la publicación más difundida entre todas las de carácter religioso y la de mayor influencia entre los hombres y mujeres del régimen (Sánchez 2015, 754). Fundada en 1941 por el Cardenal Gomá, fue concebida como órgano informativo de la Dirección Central de la ACE y gradualmente se transformó en la portavoz oficiosa de la Iglesia en España. Ecclesia era una revista de periodicidad mensual y tenía un coste de 1,25 pesetas. En esta revista fue común la orientación hacia las mujeres, conformándose como instrumento de difusión de modelos de feminidad que buscaba el franquismo. Esta revista tenía como principal objetivo dar a conocer al gran público «el pensamiento pontificio, facilitar una formación religiosa moderna completa y sistemática, para conocer las [...] lecturas de tipo popular de figuras relacionadas con la caridad». ${ }^{19}$

Aunque el público lector de Ecclesia no fuese específicamente el femenino, esta revista buscó publicitar el papel de la mujer como dirigente moral en el ámbito privado: la mujer era quien «dirigía» el hogar, la que sabía «vivir» la vida del hogar, limpiar, hacer agradable la casa y era quien cuidaba de las lecturas de las bibliotecas familiares. Asimismo, las mujeres católicas debían sentir el «amor» al hogar, además de hacer atrayente el nido familiar a su marido y a ser, sobre todo, madres. Por ello, a lo largo de las páginas de la revista había lecciones de hogar y enseñanzas patrióticas de santas (como Nuestra Señora del Puy o Nuestra Señora de Fátima) y reinas españolas. Y se señalaba, además, que la ausencia de la figura maternal producía males gravísimos en la familia y la nación. Por ello, en 1942, se afirmaba que «frente a la tendencia anticristiana, que propugna el trabajo de la mujer fuera de su casa, la teoría cristiana abogaba por la mejor retribución al padre de familia y la presencia de la mujer en el hogar».$^{20} \mathrm{El}$ objetivo principal era alcanzar el «salario familiar», responsabilidad exclusiva del varón bajo el arquetipo de masculinidad del breadwinner, es decir, el ideal de masculinidad conceptualizado como el ganador del pan (Aresti 2005, 76-77).

Por otra parte, es importante tener en cuenta que la identificación de la Iglesia con la dictadura no estuvo exenta de tensiones, en especial durante los primeros años de la posguerra, cuando el protagonismo de la Falange fue predominante, sobre todo en lo relativo a las políticas de lectura. En este sentido, Ecclesia argumentaba que no se podía fiar de todo a los organismos estatales que realizaban la censura y reclamaba una acción más enérgica del Estado, dada las consecuencias cívico-sociales que los «focos» de corrupción habían traído consigo. También se argumentaba que las leyes en relación a la censura de libros y revistas no se cumplían, como ocurría en la Italia de Mussolini, donde las denuncias de circulación

Ecclesia, 1951.

Ecclesia, 1942, 14. En la cultura franquista, la legislación mantendría estos ideales del modelo masculino como «ganador del pan» y para las mujeres el de ama de casa, especialmente durante el primer franquismo (Saénz del Castillo Velasco 2015, 33). 
de novelas, revistas y libros obscenos eran frecuentes. ${ }^{21}$ La Iglesia se consideraba la única institución capaz de promover la buena lectura a las mujeres: había que educarlas en el sentido patriótico y religioso con el fin de suplantar, en definitiva, «la filosofía nebulosa». ${ }^{22}$

Por ello, desde las páginas de Ecclesia, se intentó complementar el discurso falangista, mediante un sistema de orientación bibliográfica y de opiniones sobre la lectura y el papel de las mujeres. El discurso domesticado de la Sección Femenina de la Falange sobre la feminidad no fue diferente al de la Iglesia Católica, pero la Falange le otorgó a la mujer más agencia en temas sociales (tanto públicos como privados), convirtiendo a las falangistas en una especie de «madres sociales» (Morcillo 1999, 623; Gahete Muñoz 2013).

Aunque la censura gubernamental estuviese bajo control de la Falange hasta el inicio de la década de 1940, Ecclesia, mediante su influencia entre los lectores católicos, conseguía reducir la circulación de ciertas obras. Así, en 1942, las Mujeres de la Acción Católica montaron una exposición de libros infantiles, ya que había que evitar que los niños accediesen a los libros que «extravíen el entendimiento o corrompan el corazón». ${ }^{23}$ Ecclesia afirmaba que los padres nunca habían podido contar con un servicio de orientación que les asesorase de una manera segura sobre la calidad moral de algunas obras para niños. En una exposición, 31 tomos fueron seleccionados para ser recomendados a los padres. Había libros de cuentos, de fantasía, de formación religiosa y moral, todas adecuadas para niños y muchachos, como ediciones infantiles de la Biblia, los misales y la vida de santos.

Las mujeres de la ACE se tornaban así en una especie de censoras de la literatura infantil y de las bibliotecas familiares. Las Mujeres de la ACE se mostraron, pues, muy activas en el campo de la orientación de las lecturas para niños, muy especialmente a través del Secretariado de Niños. De allí partió la elaboración de críticas de libros religiosos para orientar a los Consejos Diocesanos en la edición de lecturas para niños y muchachos (Echalecu 2015, 1442). La literatura infantil se había convertido en una proyección del Nuevo Estado y de su Cruzada, y las Mujeres de la ACE en sus guardianas. Se justificaba, así, la necesidad de elaborar indicaciones «orientativas» para los lectores, puesto que «la Inquisición es una forma de defensa que practican desde hace muchos años todas las naciones del mundo». ${ }^{24}$ Además, se afirmaba que una ojeada superficial a los escaparates de las librerías daría como resultado una lista no corta de obras reprobables y contrarias al espíritu del nacionalcatolicismo. ${ }^{25}$ En este sentido, la idea defendida bajo estos argumentos era la total responsabilidad de las mujeres en la situación del hogar y de los niños, al ser ellas las protectoras de la fe católica en ámbito privado.

\footnotetext{
Ecclesia, 1942, p. 3.

Ecclesia, 1942, p. 819.

Ecclesia, 1949, p. 17

Ecclesia, 1942, p. 867.

Ecclesia, 1942, p. 2.
}

ex æquo, n. ${ }^{\circ}$ 37, 2018, pp. 63-80. DOI: https://doi.org/10.22355/exaequo.2018.37.05 
Con el fin de institucionalizar y dar coherencia a la censura de publicaciones, como se venía haciendo en las páginas de la revista, el 17 de enero de 1942 se inauguró la sección «Orientaciones bibliográficas». Ecclesia quería poner a sus lectores al corriente del movimiento bibliográfico y orientarlos de manera más eficaz. En dicha sección, Ecclesia frecuentemente señalaba su preocupación por las novelas rosas y las novelas verdes. Ambos géneros eran muy leídos por las mujeres y muchachas españolas, y la ACE los consideraba muy nocivos, ya que tenían poco que ver con la «entereza de la vida cristiana», pues «no suele encontrarse en tal ambiente la robustez espiritual, el temple acerado con que la religión hace profundos a los hombres». ${ }^{26}$ Es importante señalar que, concretamente, este tipo de novela recreativa cubría más de la mitad de las publicaciones anuales y que las mujeres que aparecían en la novela rosa lo hacían desde un mundo de grandes contradicciones, donde primaban el ideal amoroso y el matrimonio (Peinado Rodríguez y Anta Félez 2013).

\section{A modo de conclusión}

Las distintas publicaciones de la Acción Católica analizadas en este trabajo reflejan las complejas intricaciones entre los discursos de género fomentados por esta institución. Por una parte, en las tres revistas, la ACE buscó sustentar sus discursos en los pilares del catolicismo más tradicional y en la defensa de unos arquetipos que relacionaban las mujeres con la familia y los cuidados y con el paradigma de la Virgen María. Esta ideología ligaría a solteras y casadas al hogar, y, en la medida de lo posible, alejaría a éstas del mundo del trabajo extradoméstico, incluidas a las obreras.

Para jóvenes y adultas, de clase obrera o acomodada, la ACE definió en sus revistas un arquetipo de género prácticamente idéntico en contenido, adaptando para cada tipo de público únicamente el formato de la revista, el estilo, algunos contenidos y el lenguaje. De hecho, sin la movilización de las católicas y su labor proselitista, coordinada a través del secretariado encargado de la propaganda, y de la puesta en marcha del Secretariado de Obreras, la divulgación de este modelo ideológico de género no hubiera sido posible. Así, de acuerdo con Inmaculada Blasco Herranz (2005a y 2008c), al ser ellas las encargadas de la educación de los hijos y del cuidado del hogar traería consigo paralela y paradójicamente una movilización activa de las católicas.

El paternalismo ejercido por las Mujeres de la ACE sobre las obreras queda reflejado en la potestad que ejercieron las «damas», al editar al completo la revista Para Nosotras desde su Consejo Superior. Mayor autonomía tenían las jóvenes católicas, pues el Consejo Superior de Jóvenes de Acción Católica era el encargado de la publicación de Volad, con plena potestad sobre sus contenidos. A pesar de

$26 \quad$ Ecclesia, 1943, p. 3-4. 
que las jóvenes disfrutasen de una mayor autonomía dentro de la ACE después de su emancipación (Pérez del Puerto, 2012, 6), lo cierto es que fueron precisamente las obreras quienes, sin definir de su puño y letra los modelos de género, cobraron un protagonismo mayor en estos años y encontraron mayores contradicciones entre los discursos y sus actuaciones cotidianas. De hecho, la HOACF no tendría hasta cinco años después de su nacimiento una presidenta nacional de origen obrero, Juliana Gómez Herradón, ni tampoco editaría una revista propia en su Comisión Nacional hasta el inicio de la década de 1950 con la Hoja Sara.

Las revistas y boletines de la ACE difundieron un único modelo de género enunciado para mujeres de distintas clases, independientemente de su situación familiar o económica. Sin embargo, las diferencias en el origen social, las situaciones cotidianas que vivían las mujeres bajo el franquismo y el desigual acceso a la educación, dificultaron que ellas asumieran de manera homogénea estos discursos. Serían las obreras las que encontrarían más contradicciones entre los discursos teóricos y su realidad próxima para cumplir con sus deberes de madres y esposas y abandonar cualquier tipo de trabajo extradoméstico.

En las tres revistas editadas a cargo de la Acción Católica, también podemos ver el papel central desempeñado por las mujeres y las jóvenes católicas en la esfera pública. La revista Ecclesia revela la importancia clave que las mujeres adultas tenían en relación con la coordinación y orientación de las lecturas para los niños; las católicas así se tornaban guardianas de las buenas lecturas y censoras de las malas. En la revista Volad, las jóvenes solían ser las escritoras de los artículos de la revista, y en sus secciones, como en la «Para qué sirves», se presentaban diferentes carreras profesionales para las muchachas que iban más allá del espacio doméstico. Y, por fin, en Para nosotras, revista dirigida a las obreras católicas, se animaba a que éstas participaran en distintas actividades públicas y se sumasen a la recién formada HOACF, la rama obrera de especialización femenina de la ACE.

Así, existió una interrelación entre los espacios públicos y privados, y las tres revistas demuestran claramente que no se podía separar de forma tajante los discursos sobre el rol de las mujeres en las diferentes esferas de la sociedad franquista. El espacio público y el desarrollo de la sociedad en su conjunto se verían profundamente afectados por la actividad femenina. Precisamente en este artículo se pretendió señalar, en sintonía con otros trabajos como los de Mónica Moreno e Inmaculada Blasco, que los discursos no siempre fueron asumidos totalmente por las mujeres, y que su participación en diferentes ramas del movimiento católico supuso para muchas una experiencia vital nueva. Adelaide Coari y Miren Llona destacaron la importancia evolutiva de la militancia católica de las mujeres, siendo de esta forma que las mujeres que se inician en el movimiento católico lo hacen en un primer momento desde el discurso de «las mujeres para la familia» para posteriormente evolucionar, gracias a sus actividades eclesiales, al modelo de «mujer para la sociedad» (Llona 1998, 294). 


\section{Referencias bibliográficas}

Álvarez Rodrigo, Álvaro. 1999. «La reorganización de la Unión de Mujeres de Acción Católica en la diócesis de Valencia (1939-1951)». En Tiempos de silencio. Actas del IV Encuentro de Investigadores del Franquismo, Valencia, Universidad de Valencia, 140-145.

Aresti, Nerea. 2005. «Ideales y expectativas: la evolución de las relaciones de género en el primer tercio del siglo XX». Gerónimo de Uztariz 21, 67-80.

Botti, Alfonso. 1992. Cielo y dinero. El nacionalcatolicismo en España (1881-1975). Madrid: Alianza Editorial.

Blasco Herranz, Inmaculada. 2003. Paradojas de la ortodoxia: política de masas y militancia católica femenina en España (1919-1939). Zaragoza: Universidad de Zaragoza.

Blasco Herranz, Inmaculada. 2005a. «Género y religión: de la feminización de la religión a la movilización católica femenina. Una revisión crítica». Historia Social 53, 119-136.

Blasco Herranz, Inmaculada. 2005b. «'Sección Femenina' y 'Acción Católica' la movilización de las mujeres durante el franquismo», Gerónimo de Uztariz 21, 55-66.

Blasco Herranz, Inmaculada. 2005c «Dones i activisme catòlic: 1’Acción Católica de la Mujer entre 1919 i 1950». Recerques: Història economía i cultura 51, 115-139.

Blasco Herranz, Inmaculada. 2008a. «Las ramas femeninas de la AC durante la II República: de la política al apostolado». En La Acción Católica en la II República, editado por Feliciano Montero, 43-72. Alcalá de Henares: Universidad de Alcalá.

Blasco Herranz, Inmaculada. 2008b. «Mujeres y 'cuestión social' en el catolicismo social español: los significados de la 'obrera' ». Arenal 15 (2), 237-268.

Colmenero Martínez, Ricardo. 2014. «Iglesia católica y cine en el franquismo: tres perspectivas para un proyecto». Historia Actual Online 35, 143-151.

Di Febo, Giuliana. 2004. «La Cruzada y la politización de lo sagrado. Un Caudillo providencial». En Fascismo y franquismo cara a cara, 83-97, editado por Javier Tusell, Emilio Gentile, Giuliana Di febo y Susana Sueiro. Madrid: Biblioteca Nueva.

Echalecu, Ana María Rodrigo. 2015. «La política del libro de Falange y Acción Católica durante la primera década del franquismo». En Actas del XII Congreso de la Asociación de Historia Contemporánea, 1429-1450.

Gahete Muñoz, Soraya. 2013. «Las mujeres como transmisoras de la ideología falangista». Cuadernos Kóre 8, 17-43.

Llona, Miren. 1998. «El feminismo católico en los años veinte y sus antecedentes ideológicos». Vasconia: Cuadernos de historia-geografía 25, 283-299.

Martín Gutiérrez, Sara. 2016. «Las mujeres en la acción social cristiana. De la caridad nacional católica al compromiso social. 'La puesta en marcha de las obreras hacia un mundo mejor'», Itinerantes 6, 65-88.

Martín Gutiérrez, Sara. 2017a. Obreras y católicas. De la formación a la movilización. Roles de género y compromiso temporal de la Hermandad Obrera de Acción Católica Femenina (HOACF) en España (1946-1970). Tesis doctoral, Universidad Complutense de Madrid. Disponible en http://eprints.ucm.es/45468/

Martín Gutiérrez, Sara. 2017b. «Conquistando las almas y el hogar. Las mujeres de la primera HOACF durante la dictadura franquista: entre la espiritualidad y la acción». En Actas del IX Encuentro Internacional de Investigadores del Franquismo. 80 años de la Guerra Civil Española, CD-ROM dirigido por Teresa Ortega López y Eloísa Baena. Sevilla: Fundación Estudios Sindicales y Cooperación Andalucía pp. 451-460.

Maza Zorilla, Elena. 2014. «El mito de Isabel de Castilla como elemento de legitimidad política en el franquismo». Historia y Política 31, 167-192. 
Mínguez Blasco, Raúl. 2014. La paradoja católica ante la modernidad: modelos de feminidad y mujeres católicas en España. Tesis Doctoral, Universidad de Valencia.

Montero, Feliciano. 2009. «La Acción Católica, Ángel Herrera y la Asociación Católica de Propagandistas». En Laicismo y catolicismo. El conflicto político-religioso en la Segunda República, editado por Julio de la Cueva y Feliciano Montero. 159-179. Alcalá de Henares: Universidad de Alcalá.

Morcillo, Aurora. 1999. «Shaping True Catholic Womanhood. Francoist Educational Discourse on Women». En Constructing Spanish Womanhood: Female Identity in Modern Spain, editado por Victoria Enders y Pamela Radcliff, 51-70. Albany, NY: State of New York University Press.

Morcillo, Aurora. 2012. «Españolas: femenino/mismo plural (1900-1940)». En 100 años en femenino, 53-77, editado por Isabel Tejeda y Oliva María Rubio. Madrid: Acción Cultural Española.

Morcillo, Aurora. 2005. «Religiosas y laicas en el franquismo entre la dictadura y la oposición». Arenal 12 (1), 61-89.

Morcillo, Aurora. 2011. «Mujeres, trabajadoras y católicas: la HOACF en el franquismo». En De la cruzada al desenganche: la iglesia española entre el franquismo y la transición, coordinado por por Manuel Ortiz Heras y Damián A. González, 133-159. Madrid: Sílex.

Morcillo, Aurora. 2012. «Mujeres en la Acción Católica y el Opus Dei. Identidades de género y culturas políticas en el catolicismo de los años sesenta». Historia y política: ideas, procesos y movimientos sociales 28, 167-194.

Moreno Seco, Mónica. 2003. «De la caridad al compromiso: las Mujeres de Acción Católica (1958-1968)», Historia Contemporánea 26, 239-265.

Muñoz Ruiz, María del Carmen. 2002. Mujer mítica, mujeres reales: Las revistas femeninas en España (1955-1970). Tesis doctoral. Universidad Complutense de Madrid. Disponible en: https://biblioteca.ucm.es/tesis/ghi/ucm-t26317.pdf.

Muñoz Ruiz, María del Carmen. 2003. «Las revistas para mujeres durante el franquismo». En Mujeres y hombres en la España franquista: sociedad, economía, politica y cultura, editado por Gloria Nielfa, 95-144. Madrid: Editorial Complutense.

Orbegozo Urruela, Ángel. 1957. La prensa de la Iglesia en España: datos primarios de la Oficina Estadística de la Iglesia. Oficina Estadística de la Iglesia: Madrid.

Ortega López, Margarita. 1988. «Casa o convento: la educación de la mujer en las edades Moderna y Contemporánea». Revista Historia, 16 (145), 41-48.

Peinado Rodríguez, Matilde, y José Luis Anta Félez. 2013. «Educar para el matrimonio en femenino: modelos y prácticas en la literatura de la posguerra». Athenea Digital 13 (2), 34-46. DOI: https://doi.org/10.5565/rev/athenead/v13n2.892

Pérez del Puerto, Ángela. 2012. «Acción Católica femenina: La rama juvenil como instrumento de control de la adolescencia en los años cuarenta». En No es País para Jóvenes, coordinado por Alejandra Ibarra Aguirregabiria. Actas del III Encuentro de Jóvenes Investigadores en Historia Contemporánea (Granada, 2009), AHC, UPV e Instituto Valentín de Foronda, 1-12.

Pérez del Puerto, Ángela. 2015. Más allá de las naciones. La defensa de la feminidad católica a través del proyecto educativo de Acción Católica en España y Estados Unidos (1940-1950). Madrid: Universidad Autónoma de Madrid.

Preziosi, Ernesto. 1996. Obbedienti in piedi: la vicenda dell'Azione cattolica in Italia. Torino: SEI. Salas, Mary. 1959. Nosotras las solteras. Barcelona: Juan Flors.

Salomón Chéliz, María Pilar. 2000. «Mujeres, religión y anticlericalismo en la España contemporánea: ¿para cuándo una historia desde la perspectiva de género?». En El siglo XX: balances y perspectivas, editado por Álvarez et al. Valencia: Fundación Cañada Blanch. 
Saénz del Castillo Velasco, Aritza. 2015. Las damas de hierro. La participación de las mujeres en el mercado laboral de Vitoria-Gasteiz (1950-1975). Bilbao: Universidad del País Vasco.

Sánchez, Carlos Nieto. 2015. «Las editoriales católicas y los libros religiosos». En Historia de la edición en España, 1939-1975, editado por Jesús Martínez Martín. Madrid: Marcial Pons.

Saz Campos, Ismael. 2003. España contra España. Los nacionalismos franquistas. Madrid: Marcial Pons.

Saz Campos, Ismael. 2013. Las caras del franquismo. Granada: Comares.

Silva, Carmen. 2013. «O desafio das publicações feministas». Revista Estudos Feministas 21 (2), 625-635. DOI: https://doi.org/10.1590/S0104-026X2013000200014

Vilanova Ribas, Mercedes, y Xavier Moreno Juliá. 1992. Atlas de la evolución del analfabetismo en España de 1887 a 1981. Madrid: Ministerio de Educación y Ciencia.

Sara Martín Gutiérrez. Licenciada en Periodismo y doctora en Historia Contemporánea por la Universidad Complutense de Madrid, con mención europea por la Università degli studi di Firenze. Dentro de sus líneas de investigación se encuentran la historia de las relaciones de género y la historia de las mujeres. Ha analizado las relaciones de las ramas de Mujeres de la Acción Católica con el movimiento obrero desde una óptica transnacional, a través de la agencia de las trabajadoras textiles en España y Argentina. Asimismo, ha participado en numerosos congresos nacionales e internacionales y realizado varias estancias de investigación en la Universidad de Buenos Aires, donde cursa actualmente un programa posdoctoral en la facultad de Filosofía y Letras.

Gabriela de Lima Grecco. Desde febrero de 2018, es Investigadora Postdoctoral de la UAM a través de los contratos de Atracción de Talento Investigador, Comunidad de Madrid. Licenciada en Historia y doctora en Historia Contemporánea por la Universidad Autónoma de Madrid (UAM), con mención internacional por la University of California de Los Ángeles (UCLA). Dentro de sus líneas de investigación se encuentran la historia comparada entre las dictaduras de Getúlio Vargas (Brasil) y de Francisco Franco (España), sus políticas culturales, la censura y la promoción literaria, así como las mujeres escritoras y premiadas bajo dictaduras fascistas of fascistizadas.

Artículo recibido el 28 de noviembre de 2017 y aceptado para publicación el 26 de marzo de 2018. 